\title{
A case of non-pueperal chronic uterine inversion managed successfully
}

\author{
Michelle Fonseca, Ashwini Desai*, Deepali Kapote, Swati Gawai, Anam Syed
}

Department of Obstetrics and Gynecology, LTMMC and LTMGH, Mumbai, Maharashtra, India

Received: 10 November 2020

Accepted: 11 December 2020

\section{*Correspondence:}

Dr. Ashwini Desai,

E-mail: asdesai111@gmail.com

Copyright: (c) the author(s), publisher and licensee Medip Academy. This is an open-access article distributed under the terms of the Creative Commons Attribution Non-Commercial License, which permits unrestricted non-commercial use, distribution, and reproduction in any medium, provided the original work is properly cited.

\begin{abstract}
Uterine inversion is prolapse of the uterine fundus and corpus turned inside out towards or through the cervix. The nonpuerperal type of uterine inversion is a quite rare occurrence and it accounts for only $17 \%$ of all uterine inversion cases. We present a case of 45 year old multiparous female who presented to us with polymenorrhagia with fibroid polyp. Ultrasonography confirmed the clinical findings however Intraoperatively examination under anaesthesia revealed uterine inversion. On table we proceeded with Haultains method of uterine reposition followed by total abdominal hysterectomy. Patient recovered well and thus case was successfully managed.
\end{abstract}

Keywords: Uterine inversion, Haultains method, Polymenorrhagia

\section{INTRODUCTION}

Uterine inversion is prolapse of the uterine fundus and corpus turned inside out towards or through the cervix. Most commonly uterine inversion is seen in the postpartum period. The non-puerperal type of uterine inversion is a quite rare occurrence and it accounts for $17 \%$ of all uterine inversion cases. ${ }^{1}$ Fundal fibroid polyp is the etiology in majority of cases and menorrhagia being the most common clinical feature along with mass per vaginum.

\section{CASE REPORT}

A 45 year old female P4L4 with history of all vaginal deliveries presented to our outpatient department (OPD) with complaints of heavy menstrual bleeding and polymenorrhea since past one year. There was no history of any medical or surgical illness. On general examination pallor was noted. The abdomen was soft on examination. On per speculum examination a mass of size $5-6 \mathrm{~cm}$, protruding through the cervix was noted. The mass was red and congestion noted all over it. On per vaginum examination the mass was felt which was soft to firm in consistency and bleeding on touch and the pedicle was also felt higher up (arising from uterus). Rim of cervix felt around the mass and uterus was 12-14 weeks size. A diagnosis of fibroid polyp was made and the patient was admitted for further evaluation and correction of anaemia and management of the fibroid polyp.

On haemoglobin of $7 \mathrm{~g} \%$ patient was transfused 3 pint packed red cells (PRC). All routine investigations were done. The routine blood investigations were within normal limits. Ultrasonography was suggestive of $6 \times 5 \times 4 \mathrm{~cm}$ sized hypoechoic lesion in anterior wall of lower uterine segment pushing ET posteriorly suggestive of fibroid. After doing the preoperative work up, patient was posted for vaginal myomectomy.

Intraoperatively the mass was held with two vulsellum and attempt was made to twist the mass and get to the base of the pedicle. However to our surprise a plane was found between the fibroid polyp and inverted uterine fundus was thus diagnosed. Therefore after the fibroid was removed vaginally, decision to proceed with exploratory laparotomy to confirm and correct the inversion was taken. On laparotomy a dimple was noted at the site of the fundus with both the fallopian tubes pulled inside and diagnosis 
of uterine inversion confirmed. The following image shows the intraoperative findings on laparotomy.

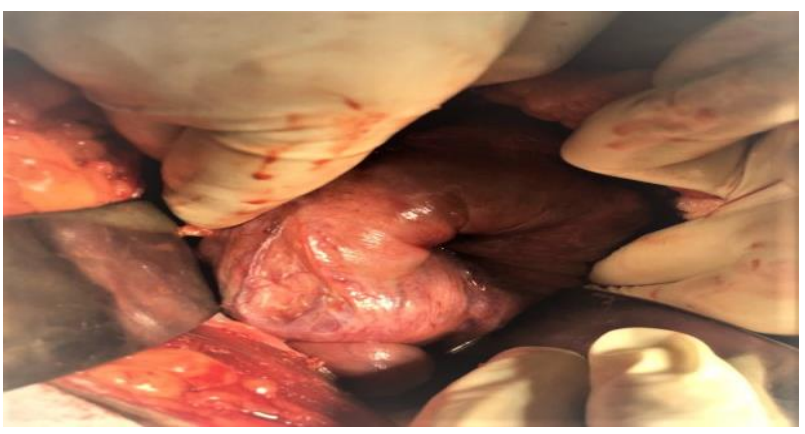

Figure 1: Dimple in the uterine fundus, characteristic of uterine inversion.

Initially we attempted to reposit the uterus vaginally by Johnsons method and Huntington method by applying traction on round ligaments but were unable to reposit the fundus because of the tight constriction ring thus we decided to proceed with the Haultains method by incising the cervical constriction ring posteriorly and by gentle instrumental traction on the round ligament and this was aided by upward pressure on the fundus vaginally. The given two images show the attempt at reposition by traction and then by making an incision on posterior aspect of the constriction ring.

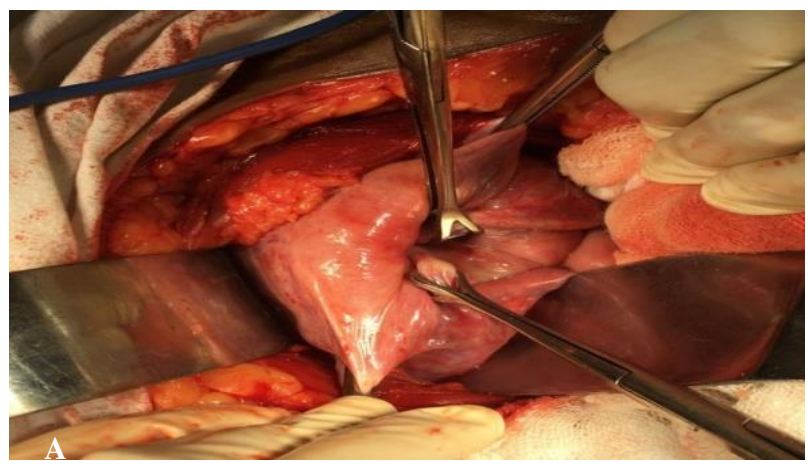

Figure 2: Attempt to correct inversion by traction on the round ligaments.

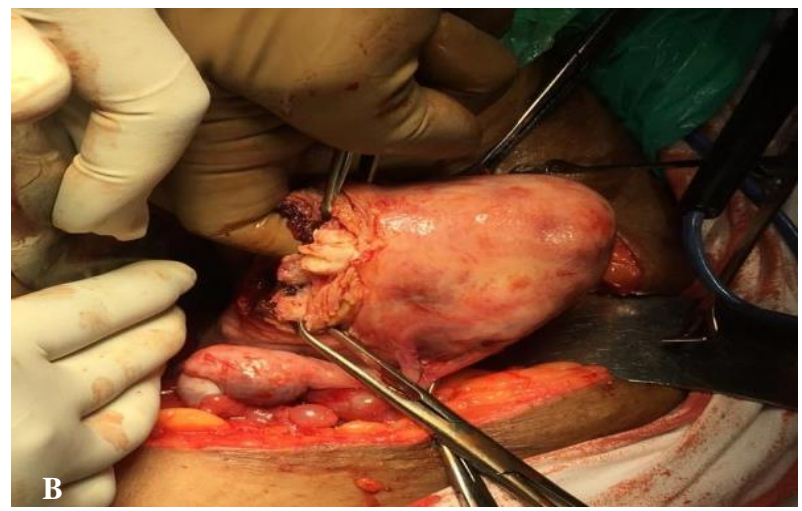

Figure 3: Uterus reposited by excising the constriction ring posteriorly.
Once the uterus was successfully reposited we went ahead with total abdominal hysterectomy and the specimen was sent for histopathological examination. Patient withstood the procedure well and the postoperative course was uneventful. Patient was discharged on day 7 of the procedure and was able to resume her work within a week.

\section{DISCUSSION}

Non-puerperal uterine inversion is usually precipitated by tumours sited at the fundus of the uterus which exert traction force to cause the inversion, although some cases have been reported without associated tumours. Usually, the cases of non-puerperal uterine inversion present after 45 years, also are mostly due to benign myomas though rarely associated with malignancies. ${ }^{1}$ Only few cases of non-puerperal inversions have been reported in young women and in most cases the aetiology is attributed to malignancy. ${ }^{2}$ Uterine leiomyoma are known to cause inversion in $78-85 \%$ of cases. ${ }^{3}$ The major precipitating factors are tumour attachment site, thickness of the tumour pedicle, tumour size, thin uterine wall and dilatation of the cervix. ${ }^{4}$ Studies done by Mwinyoglee et al suggest that $97 \%$ cases of non-puerperal inversion were associated with tumours and of which $20 \%$ were malignant. ${ }^{5}$ Thus the need for conducting histopathology studies on all samples cannot be over emphasized.

Based on the degree of inversion, genital inversion can be classified in to partial and total, though inversion can further be divided into four distinct stages. ${ }^{6}$ They are as follows: first- inverted uterine wall does not protrude through the cervix, second-inverted uterine wall protrudes through the cervix but not out of introitus, inverted uterine fundus protrudes through the introitus, and total inversion i.e. both uterus and vagina are inverted.

Based on the onset and evolution, non-puerperal uterine inversion can also be classified into acute and chronic. Though chronic cases are insidious presenting with pelvic discomfort, irregular vaginal bleeding and anaemia, the acute cases can be dramatic characterised by severe pain and haemorrhage. ${ }^{7}$

The diagnosis is difficult and requires high index of clinical suspicion. Clinical diagnosis is easier when the inversion is complete but it has to be differentiated from procidentia. ${ }^{8}$ One useful investigation for diagnosis is T2weighted magnetic resonance imaging (MRI) scans. Signs indicative of uterine inversion are - a U-shaped uterine cavity, thickened and inverted uterine fundus on a sagittal image and a 'bulls-eye' configuration on an axial image. ${ }^{9}$

Treatment is by reposition. If there is a tumor it has to be biopsied to rule out malignancy. If the tumor is benign like fibroid it can be preserved prior to hysterectomy, to prevent blood loss due to myomectomy. However one can first proceed with myomectomy to permit easy reposition. Reposition procedures like that of Johnson are more likely to be successful in acute inversion but in chronic cases, 
surgery is imperative. Depending on the patients reproductive desire and associated conditions, surgical reposition or hysterectomy could be considered. Surgical procedures are either by abdominal or vaginal route. Abdominal route is easier and generally the preferred one as it is also the safer option. Abdominal approaches include Huntington's and Haultain. In Huntington's procedure gentle traction is applied on the round ligaments and pulling up till inversion is corrected. Vaginal approaches include Kustner and Spinelle. Kustner procedure includes entering the pouch of Douglas vaginally and splitting the posterior aspect of the uterus and cervix and finally re-inverting the uterus where as in Spinelli's method incision is given in anterior aspect of cervix and uterus is reinverted. ${ }^{10}$

\section{CONCLUSION}

Though non-puerperal uterine inversion is uncommon, the few cases will still have to be managed without prior experience. High index of suspicion for the diagnosis and clear knowledge about gynaecological surgery will permit a successful outcome.

Funding: No funding sources

Conflict of interest: None declared

Ethical approval: Not required

\section{REFERENCES}

1. Gomez-Lobo V, Burch W. Nonpuerperal uterine inversion associated with an immature teratoma of the uterus in an adolescent. Obstet Gynecol. 2008;112:708-9.
2. De Vries M, Perquin DAM. Non-puerperal uterine inversion due to submucous myoma in a young woman: a case report. J Med Case Rep. 2010;4:21.

3. Lupovitch A, England ER, Chen R. Non-puerperal uterine inversion in association with uterine sarcoma; case report in a 26-year-old and review of the literature. Gynecol Oncol. 2005;97(3):938-41.

4. Lascarides E, Cohen M. Surgical management of nonpuerperal inversion of the uterus. Obstet Gynecol. 1968;32:376-81.

5. Mwinyoglee J, Simelela N, Marivate M. Non puerperal uterine inversions: a two-case report and review of the literature. Central African J Med. 1997;43:268.

6. Skinner GN, Louden KA. Nonpuerperal uterine inversion associated with an atypical leiomyoma. Aust N Z J Obstet Gynaecol. 2001;4:100-1.

7. Gowri V. Uterine inversion and corpus malignancies. A historical review. Obset Gynecol Surv. 2000;55:703-7.

8. Kopal S, Seckin NC, Turhan NO. Acute uterine inversion due to a growing submucous myoma in an elderly woman: case report. Eur J Obstet Gynecol Reprod Biol. 2001;99:118-20.

9. Lewin JS, Bryan PJ. MR imaging of uterine inversion. J Comput Assist Tomogr. 1989;13:357-9.

10. Fofie C, Baffoe P. Non puerperal uterine inversion: A case report. Ghana Med J. 2010;44:79-81.

Cite this article as: Fonseca M, Desai A, Kapote D, Gawai S, Syed A. A case of non-pueperal chronic uterine inversion managed successfully. Int J Reprod Contracept Obstet Gynecol 2021;10:419-21. 